A.V. Matyuschenko

\title{
ANALYSIS OF THERMAL STATE OF TRACTION BRUSHLESS PERMANENT MOTOR FOR MINE ELECTRIC LOCOMOTIVE
}

Purpose. The study was conducted to analyze thermal state of the traction permanent magnet synchronous motor for mine electric battery locomotive when operating in continuous and short-time duty modes. These operating modes are selected for study, as they are typical for mine electric locomotives. Methodology. Thermal calculation was performed by means of FEM in threedimensional formulation of problem using Jmag-Designer. Results. The modeling results of thermal state of the PMSM in continuous and short-time duty operation modes showed good agreement with experimental results. The results showed that the temperature of PM is higher than temperature of the stator winding in continuous operation mode. It was found that PM temperature might reach excessive values because of the high presence of eddy current losses in neodymium PM. Therefore, special attention in the design and testing of PMSM should be paid to the temperature of PM in various operation modes. Practical value. It was recommended to use high temperature permanent magnets in traction PMSM to avoid demagnetization of PM and performance degradation. References 7 , tables 2 , figures 10 .

Key words: brushless motor, heat generation, temperature, losses, permanent magnet, coil, current, resistance, mathematical model, FEM.

Выполнен поверочный тепловой расчет тягового вентильного двигателя с постоянными магнитами посредством конечно-элементной цепно-полевой математической модели на платформе ЈMAG-Designer в трехмерной постановке задачи. Получено распределение температуры и графики нагрева деталей двигателя. Проведен сравнительный анализ расчетных и экспериментальных данных теплового состояния двигателя в часовом и длительном режимах работы. Библ. 7, табл. 2, рис. 10.

Ключевые слова: вентильный двигатель, нагрев, температура, потери, постоянный магнит (ПМ), катушка, математическая модель, метод конечных элементов.

Introduction. It is known that the traction motors for mine locomotives are experiencing high electromagnetic and thermal loads in difficult environments for different operating modes. This imposes certain requirements for performance since, cooling system and materials used in the engine to provide desired performance. Therefore, an important objective in the design of the traction brushless motor with permanent magnets (BMPM) is an evaluation of its thermal state which provides information on the duration of the motor operation at various modes and, if necessary, adjusts the design to ensure that the necessary requirements met [1-4].

In [5] the results of «Electrical Engineering - New Technologies» LLC (Odessa) is presented to develop and test BMPM for a mine locomotive. Overheating of the stator windings were noted during continuous operation of the BMPM as a part of the laden locomotive weight of 70.5 tons. This load corresponds to the BMPM hour mode of operation.

The goal of the paper is control thermal calculation and analysis of the thermal state of the traction BMPM [5] for mine electric battery locomotive when operating in hour and long-term modes. This analysis serves as a basis for recommendations to improve the design of the traction BMPM.

Object of investigations is the traction BMPM for a mine battery electric locomotive designed by the «Electrical Engineering - New Technologies» LLC the design of which is shown in Fig. 1. Basic geometric dimensions and winding data of BMPM are presented in Table 1. Parameters of studied operation modes are presented in Table 2.

Method of investigations. The most detailed and accurate picture of the temperature distribution it is possible to obtain by numerical methods based on the Finite Element Method. These methods make it possible to per- form the thermal calculation of the steady or transient mode of heat exchange process in the three-dimensional formulation of the problem and determine the temperature of any part of the motor $[3,4]$.

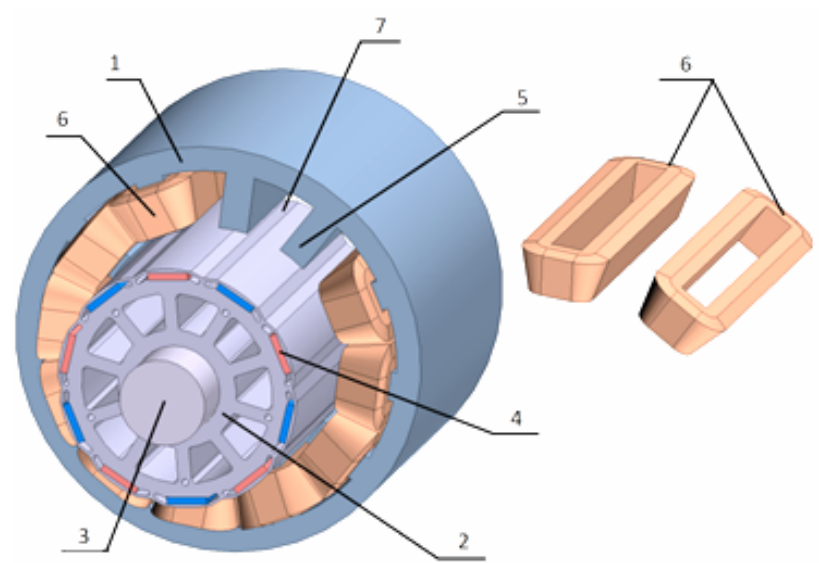

Fig. 1. Salient-pole BMPM with concentrated stator winding: 1 - stator; 2 - rotor; 3 - shaft; 4 - PM; 5 - stator pole; 6 - stator winding coils; 7 - stator slot

We present control thermal calculation of the considered BMPM in the software package for numerical computations Jmag-Designer as well as the analysis and comparison of the calculated and experimental data.

The first step of the thermal calculation is to develop a BMPM 3D model which is to be detailed enough to adequately describe the structure and properties of BMPM than should include not only the active part but the housing, shaft and slot insulation. 
Table 1 outer surface of the housing the boundary condition (the

Geometrical dimensions and winding data of the motor

\begin{tabular}{|l|c|}
\hline \multicolumn{1}{|c|}{ Name } & Value \\
\hline Stator external diameter, $\mathrm{mm}$ & 360 \\
\hline Stator internal diameter, $\mathrm{mm}$ & 217 \\
\hline Number of teeth of stator, & 12 \\
\hline Active part length, $\mathrm{mm}$ & 240 \\
\hline Number of poles of rotor & 10 \\
\hline Number of stator winding coil turns & 10 \\
\hline Dimensions of magnets $(\mathrm{NdFeB}), \mathrm{mm}$ & $240 \times 35.5 \times 6.3$ \\
\hline Air gap, $\mathrm{mm}$ & 2.5 \\
\hline
\end{tabular}

Table 2

Parameters of the BMPM operation modes

\begin{tabular}{|c|c|c|c|c|}
\hline Mode & $\begin{array}{c}\text { Torque, } \\
\mathrm{N} \cdot \mathrm{n}\end{array}$ & $\begin{array}{l}\text { Rotation fre- } \\
\text { quency, RPM }\end{array}$ & $\begin{array}{l}\text { Consumption } \\
\text { current, A }\end{array}$ & $\begin{array}{c}\text { Feeding } \\
\text { voltage, } \mathrm{V}\end{array}$ \\
\hline Hour & 210 & 600 & 130 & 120 \\
\hline $\begin{array}{l}\text { Long- } \\
\text { term } \\
(2 \\
\text { hours })\end{array}$ & 100 & 760 & 70 & 120 \\
\hline
\end{tabular}

Fig. 2 shows the prepared for calculations 3D model of the BMPM. Its parts are modeled in such a way that their sizes were close to real. It should be noted that the shape of the housing parts and the shaft is simplified but their volume equal to the real volume of parts of the BMPM investigated. This simplification allows to reduce the time spent on the creation of a 3D model at retaining the basic structure's properties for thermal calculation.

The second step is to determine the electric and magnetic losses in the motor parts. For this electromagnetic calculation of the BMPM at hour and long-term modes has been made modes taking into account losses due to eddy currents in the steel and PM.

To account the losses due to eddy currents, rotor stator and PM have been assigned the appropriate electrical resistivity.

To perform the electromagnetic calculation to the stator winding coils (SW) of the field model of the BMPM in JMAG-Designer chains editor we connected electrical circuit consisting of a constant voltage source, an inverter with pulse width modulation, voltmeters and ammeters (Fig. 3). Inverter keys control is performed using a model that implements vector BMPM control [6].

As the initial data of operation modes of the BMPM model we set voltage, rotation speed and load torque.

As a result of the electromagnetic calculation BMPM data were obtained on the losses in the stator, rotor, SW coils and PM. Loss calculation results are shown in Fig. 4 and Fig. 5.

From Fig. 4 and Fig. 5 one can see that the ratio of losses in the SW coils and PM is different for the investigated modes of the BMPM operation. At the long-term operation mode losses in PM are greater than the losses in the SW.

The third stage is proper calculation of the thermal state of the BMPM where we calculate transient motor heating process at the investigated operation modes.

For the calculation of each part corresponding heat capacity and thermal conductivity was appointed. On the
3 rd kind) of the heat transfer was set with the heat transfer coefficient of $12 \mathrm{~W} / \mathrm{m}^{2} \cdot{ }^{\circ} \mathrm{C}$ which is the average for natural convective cooling of similar motors' structures under normal conditions [7].

For each part, which is a heating source we set losses calculated earlier. Furthermore, at the calculation the dependence of electrical losses in SW on temperature has been accounted.

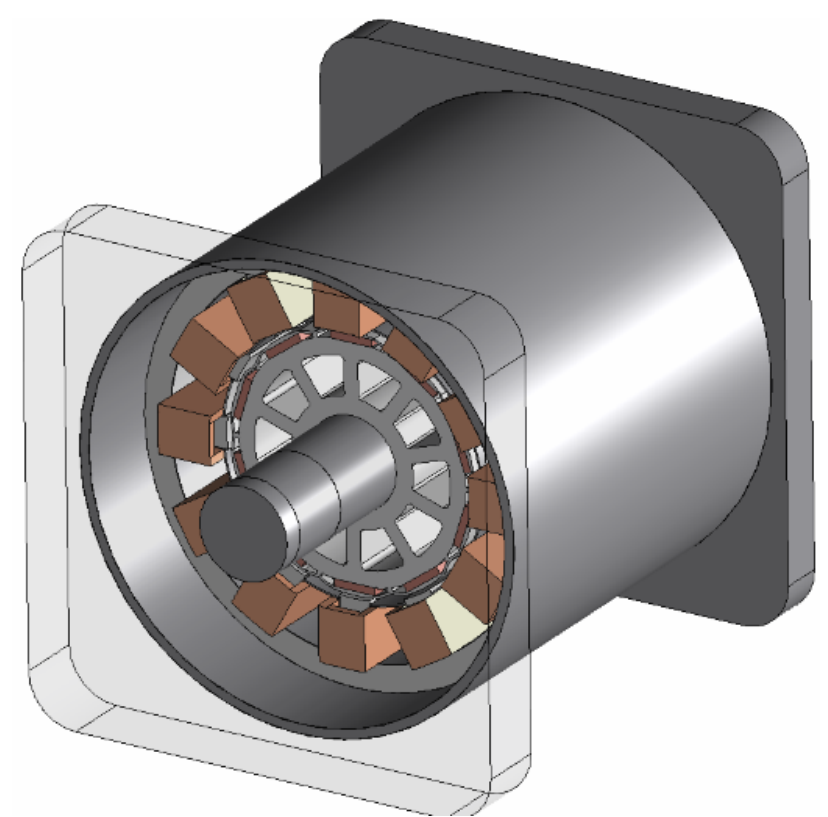

Fig. 2. 3D BMPM model with simplified housing

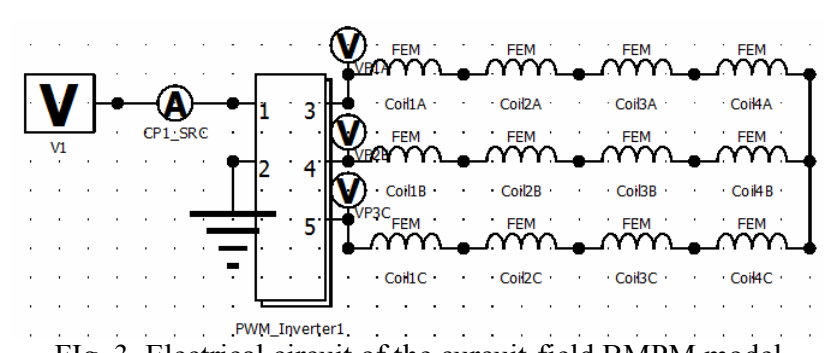

FIg. 3. Electrical circuit of the curcuit-field BMPM model

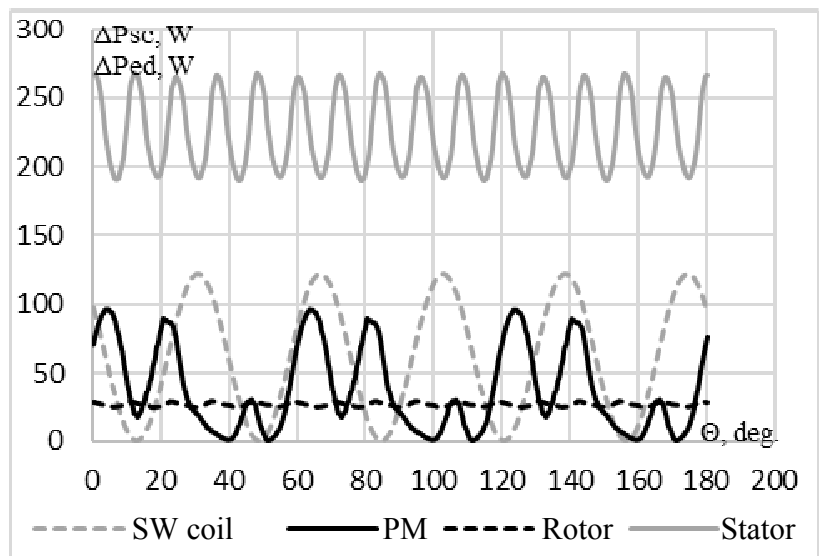

Fig. 4. Electrical $\left(\Delta P_{s c}\right)$ and magnetic $\left(\Delta P_{e d}\right)$ losses in the BMPM (hour mode) 


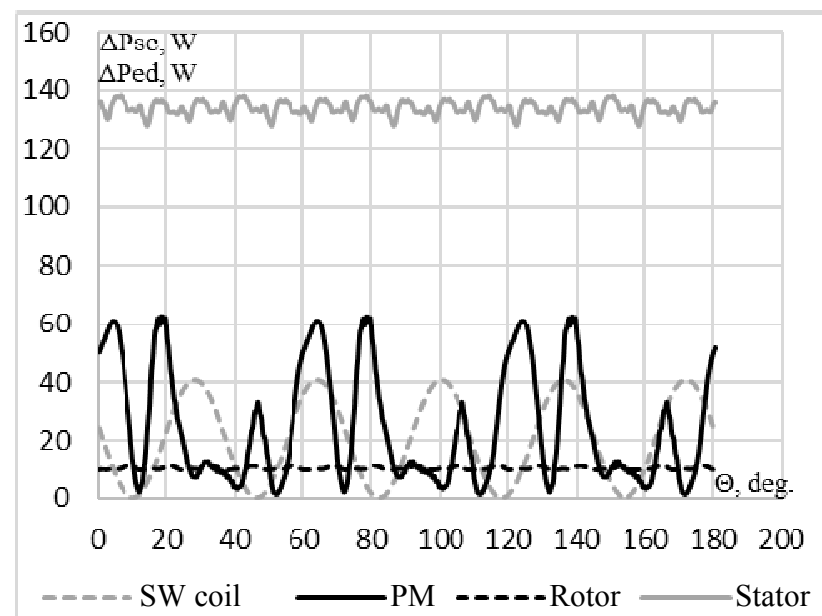

Fig. 5. Electrical $\left(\Delta P_{s c}\right)$ and magnetic $\left(\Delta P_{e d}\right)$ losses in the BMPM (long-term mode)

\section{Results of investigations.}

Fig. 6, 7 show the results of thermal calculation as the temperature distribution and heat flux vector for the hour operation mode of the BMPM. It is evident that the heat generated by the rotor and PM is removed through the shaft, and the heat of SW coils is removed through the stator and housing to the environment. This distribution of the heat flow is typical for such electric motors, which indicates the correct formulation of the problem.

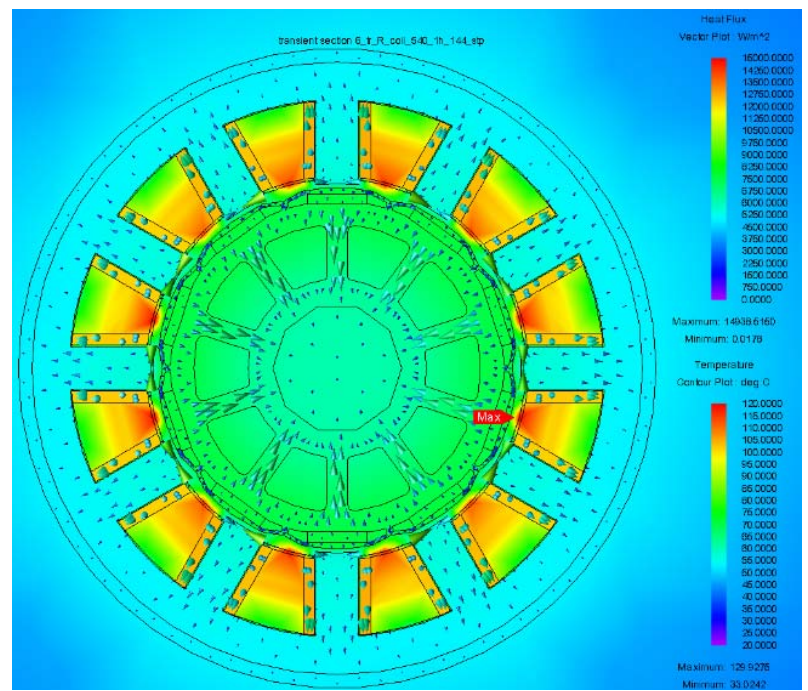

Fig. 6. Temperature and heat flux distributions (BMPM cross-section)

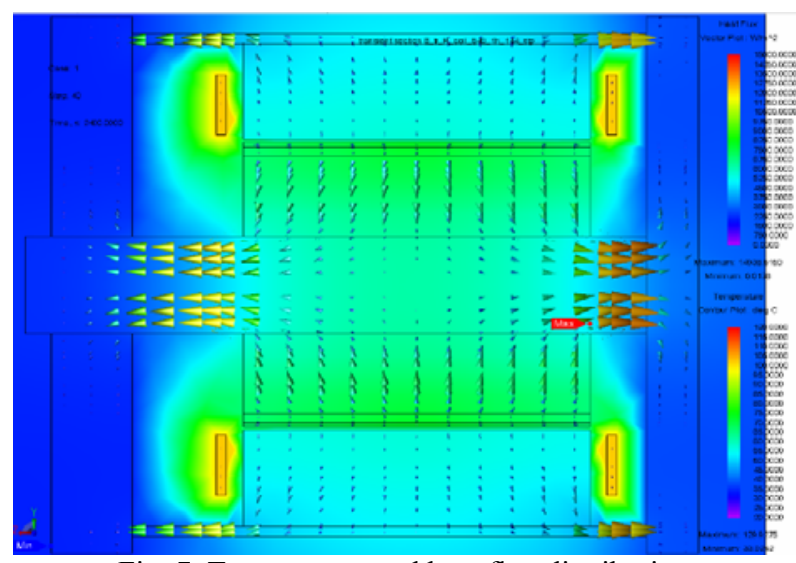

Fig. 7. Temperature and heat flux distributions (BMPM longitudinal section)
Fig. 8 compares the experimental and computational graphics of BMPM coil heating at the hour and long-term operation modes. BMPM tests were carried out on the stand of the «Energy» [5] Company.

Fig. 8 shows good agreement between the results of calculation and experiment for long-term operation. In this case the difference between the calculation and experiment does not exceed $9 \%$.

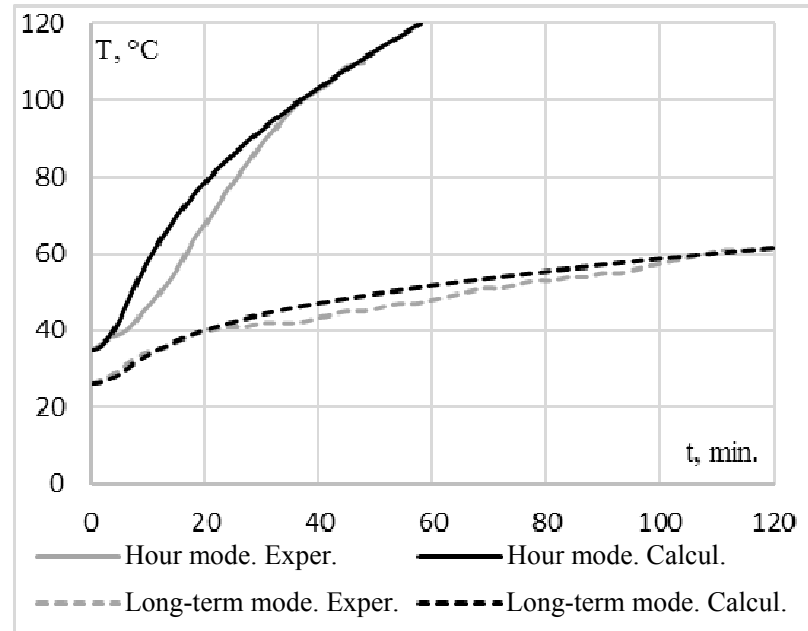

Fig. 8. SW coils heating at hour and long-term operation modes

As a result of the experiment, it was found that in 47 th minutes of operation at the hour mode of the BMPM the overheating protection tripped. In this case the winding temperature reaches $110^{\circ} \mathrm{C}$. This fact is also confirmed by the results of calculation. The maximum difference between calculation and experiment is $25 \%$. This difference can be explained by the uneven load on the duration of the experiment.

Fig. 9, 10 shows graphs of heating of the BMPM components in the hour and long-term operation. It is evident that the process of heating is different at these modes. For example, the temperature of the PM at the long-term operation during most of the estimated time exceeds the temperature of the SW coils. This can be explained by the fact that at the long-term mode, the current consumption is smaller and the rotation rate is greater than at the hour mode. As is known, the value of the magnetic losses is proportional to the frequency of magnetic reversal, and the value of the electric losses is proportional to the square of the current.

It should also be noted that at the hour operation mode the PM temperature reached $82{ }^{\circ} \mathrm{C}$ which exceeds the maximum permissible operating temperature of the low-temperature neodymium PM. Therefore, in order to avoid losing the properties of the PM and worsening performance for the investigated BMPM it is recommended to use PM with operating temperature of $120{ }^{\circ} \mathrm{C}$ and higher. 


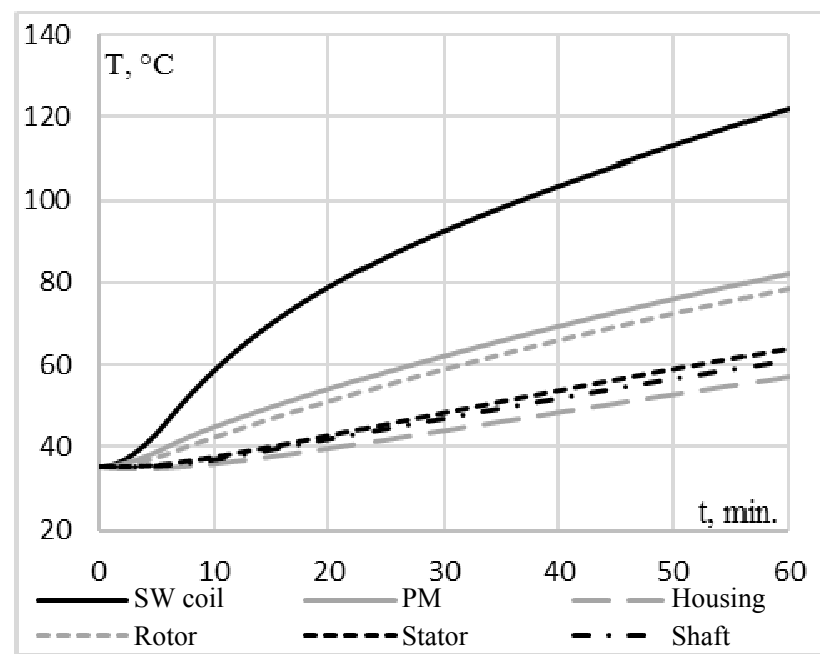

Fig. 9. BMPM parts heating (hour mode)

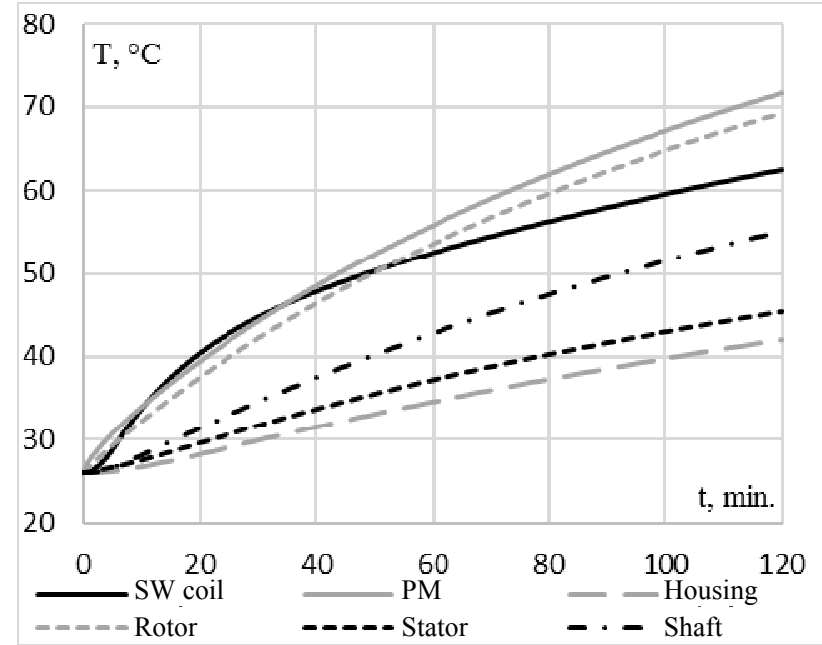

Fig. 10. BMPM parts heating (long-term mode)

Conclusions.

1. The results of the modeling of the thermal state of the BMPM at hour and long-term operation modes shown good agreement with experimental results. The difference between the calculations and experiments for the longterm mode does not exceed $9 \%$, and the maximum divergence of the calculated results and the experiment for the hour mode is $25 \%$.
2. As a result of calculations it was determined that the PM temperature may reach high values because of the presence in the PM significant eddy current losses. Therefore, special attention in the design and testing of the BMPM should be paid to the temperature of the PM at various operation modes.

\section{REFERENCES}

1. Lee S.-T., Kim H.-J., Cho J.-H., Joo D.-S., Kim D.-K. Thermal Analysis of Interior Permanent-Magnet Synchronous Motor by Electromagnetic Field-Thermal Linked Analysis. Journal of Electrical Engineering and Technology, Nov.2012, vol.7, no.6, pp. 905-910. doi: 10.5370/jeet.2012.7.6.905.

2. Mynarek P., Kowol M. Thermal analysis of a PMSM using fea and lumped parameter modeling. Czasopismo Techniczne, 2015, no.1-E(8), pp. 97-107. doi: 10.4467/2353737XCT.15.031.3831.

3. Chin Y.K., Staton D.A. Transient thermal analysis using both lumped-circuit approach and finite element method of a permanent magnet traction motor. 2004 IEEE Africon. 7th Africon Conference in Africa (IEEE Cat. No.04CH37590). doi: 10.1109/africon.2004.1406847.

4. Kefalas T.D., Kladas A.G. Finite element transient thermal analysis of PMSM for aerospace applications. XXth International Conference on Electrical Machines, Sep. 2012. doi: 10.1109/icelmach.2012.6350246.

5. Rimsha V.V., Radimov I.N., Guliy M.V., Matyuschenko A.V. Brushless motor for mining battery-electric locomotive. Electrotechnic and computer systems, 2016, vol.22(98), pp. 134138. (Rus).

6. Matyuschenko A.V. Calculation of characteristics of permanent magnet synchronous motor and their comparative analysis. Electrotechnic and computer systems, 2015, vol.19(95), pp. 101105. (Rus).

7. Borisenko A.I. Ohlazhdenie promyshlennyh jelektricheskih mashin [Cooling of industrial electric machinery]. Moscow, Energoatomizdat Publ., 1983. 296 p. (Rus).

Received 07.10.2016

A.V. Matyuschenko, Postgraduate Student, Odessa National Polytechnic University,

1, Shevchenko Avenue, Odessa, 65044, Ukraine, e-mail: sparkam@rambler.ru

\section{How to cite this article:}

Matyuschenko A.V. Analysis of thermal state of traction brushless permanent motor for mine electric locomotive. Electrical engineering \& electromechanics, 2016, no.6, pp. 15-18. doi: 10.20998/2074-272X.2016.6.03. 